\title{
An Interactive Teddy Bear Clinic Tour: Teaching student veterinarians how to interact with young children
}

Jessica S. Dalley, M.A.

Ph.D Student, Clinical Psychology: Applied Developmental Emphasis

Department of Psychology, University of Guelph,

87 Trent Lane, Guelph, ON N1G 2W1

Patricia R. Creary, B.A.

M.A. Student, Counselling \& Clinical Psychology

Department of Applied Psychology \& Human Development

Ontario Institute for Studies in Education, University of Toronto

252 Bloor St. W., Toronto, ON M5S 1V6

\section{Tiffany Durzi, DVM, CVA, CCRT, CVPP}

Primary Care Veterinary Educator

Ontario Veterinary College Smith Lane Animal Hospital, University of Guelph

48 Smith Lane, Guelph, ON N1G 2W1

Dr. C. Meghan McMurtry (PhD., C.Psych),

Assistant Professor, Clinical Psychology: Applied Developmental Emphasis

Department of Psychology, University of Guelph,

87 Trent Lane, Guelph, ON N1G 2W1

Clinical Psychologist, Pediatric Chronic Pain Program, McMaster Children's Hospital

Associate Scientist, Children's Health Research Institute

Adjunct Research Professor, Paediatrics, Western University

Link to Publisher Version: https://www.utpjournals.press/about/open-access

Correspondence concerning this article should be addressed to Jessica Dalley, Department of Psychology, University of Guelph, 87 Trent Lane, Guelph, ON N1G 2W1.

Email: jdalley@uoguelph.ca

Telephone: 519-824-4120 x52342 


\begin{abstract}
There are existing guidelines for teaching and learning skillful client communication; yet, there remains a need for integrating a developmental focus into veterinary medicine curriculum to equip students for interacting with children who accompany their companion animals. The objectives of this Teaching Tip are to: 1) describe the use of a Teddy Bear Clinic Tour as an innovative, applied practice method for teaching veterinary students about clinical communication with children, and 2) provide accompanying resources to enable use of this method to teach clinical communication at other facilities. This paper includes practical guidelines for organizing a Teddy Bear Clinic Tour at training clinics or veterinary medicine colleges, an anecdotal description of a pilot study at the Ontario Veterinary College Smith Lane Animal Hospital, and printable resources including a list of specific clinical communication skills, a sample supervisor-student evaluation sheet, recommendations for creating a child friendly-environment, examples of child-friendly veterinary vocabulary, and a sample script for a Teddy Bear Clinic Tour. Informed by the resources provided in this Teaching Tip paper, the Teddy Bear Clinic Tour can be utilized at your facility as a unique teaching method for clinical communication with children and as a community outreach program to advertise the services at the facility.
\end{abstract}

Key words: clinical education, collaborative learning, communication with veterinary students, communication with children 


\section{Introduction: Client Communication as an Essential Clinical Skill}

Communication with clients is considered an essential clinical skill in veterinary medicine. ${ }^{1,2,3}$ Improved clinical communication skills are associated with increased client satisfaction with and adherence to treatment plans, increased staff satisfaction, more ideal treatment outcomes for animals, and effective clinical problem solving. ${ }^{3,4,5,6}$ The AVMA Council on Education includes communication with clients as an important aspect of veterinary medicine curricula in order to ensure graduating students are sensitive, empathic, and effective communicators. ${ }^{1,2,3}$ Furthermore, clinical communication is a skill that has no "achievement ceiling", as one can continue to improve one's ability to communicate with different client groups throughout a career. ${ }^{3}$ Therefore, veterinary medicine colleges have the opportunity to begin their students' tenure of improving their clinical communication skills with clients by prioritizing client communication within the curriculum, providing students opportunities to practice clinical communication in an applied setting, and encouraging self-reflection as well as feedback from clinical supervisors.

As with any learned skill, a valuable way to teach effective communication to student veterinarians is by allowing them to actively practice these skills. ${ }^{6,7}$ Although learning about clinical communication in the classroom is an important first step, students can also benefit from active practice and feedback from supervisors to successfully apply these skills in real world situations. ${ }^{2,7,89}$ Furthermore, although there are existing guidelines for teaching and learning skillful client communication with adults, there remains a need for integrating a developmental focus into the curriculum to equip students for interacting with children. Families with companion animals often have children, who will likely be present during veterinary care appointments as their companion animals are very dear to them. ${ }^{10}$ Therefore, veterinarians can promote their practice as family friendly by interacting with both children and adults during appointments. Children can have a strong attachment to their companion animals, as evidenced by their reference to companion animals as family members, ${ }^{11,12}$ or peers. ${ }^{13}$ Given this bond, children naturally care about the well-being of their companion animals ${ }^{14}$ and may express this by assisting with their care, ${ }^{15}$ including attending veterinary appointments.

The overall aim of this paper is to provide an outline for using a Teddy Bear Clinic (TBC) Tour as an experiential opportunity for teaching student veterinarians' clinical communication skills for interacting with children and their families. Modeled after teddy bear tours used within the medical health profession, ${ }^{16,17}$ this innovative method has relevance for individuals at all levels of the veterinary profession, including practicing clinicians, veterinary educators and students, as well as clinical practice supervisors. Importantly, the TBC Tour format can be easily utilized within training or community clinics, and/or veterinary medicine college facilities. For this reason, the Appendices of this manuscript include practical information that will serve to assist training clinics or colleges in organizing their own TBC Tour to help student veterinarians learn about clinical communication with children and families. This paper will begin with a brief overview of the current recommendations for teaching student veterinarians about client communication, with a focus on the particular challenges of developing clinical communication skills necessary for professional relationships with children and families. Following this, a description of a pilot study of a TBC Tour at the Ontario Veterinary College Smith Lane Animal Hospital will be provided. A series of resources are provided in the Appendices (see Table 1 for a description) to enable use of a tailored TBC Tour to teach clinical communication at other facilities. Notably, when educating students on how to communicate effectively with families, it is important to emphasize specific communication skills rather than having the vague aim of improving communication overall. ${ }^{3}$ For this reason, Appendix A includes a list of specific clinical communication skills that can be incorporated as learning objectives for student veterinarians. 


\section{Clinical Communication between Veterinarians, Children, and Families}

As student veterinarians prepare for a profession in caring for animals, it is important they obtain skills in clinical communication with families who accompany their companion animals. ${ }^{1,3,18}$ Ideally, student veterinarians should be proficient in adapting their communication style to engage with clients of differing demographics; therefore, students may benefit from direct teaching regarding communication with both adult and children who own companion animals. ${ }^{2,3,4,5}$ Communicating with children can require more resourceful communication abilities, as children's capacities to understand language and health concepts can vary based on their age/developmental stage. ${ }^{19,20}$ As families with children are an important part of community veterinary practice, it is important for student veterinarians to learn to skillfully adapt their communication style to best fit the needs of their clients when children and their parents accompany their animal. ${ }^{10}$

There is strong consensus within the literature that clinical communication skills are an important component to the veterinary medicine curriculum, ${ }^{1,2,3}$ but this does not necessarily reflect actual practice ${ }^{2,3}$. In any given career, one is expected to develop an effective, professional communication style. ${ }^{9}$ For veterinarians, competence in professional communication is especially important, as veterinarians are responsible for translating veterinary jargon into lay terms, discussing emotionally intense information with clients, and providing health recommendations in a way that enhances client adherence. ${ }^{2,3,4,5}$ Communication with clients involves more than simply being kind; rather, it is about building a professional relationship with clients to ensure the veterinarian's message is being effectively expressed and the client feels his/her concerns are being acknowledged and addressed. ${ }^{4,5,6}$

While the focus of veterinary appointments is the health of the animal, it would be ideal if children who attend appointments with their parents and companion animals could be involved in conversations (when appropriate, and with permission from parents). Clinical communication with children and families can be challenging, as veterinarians will be responsible for interacting with parents, while also using language that is developmentally-appropriate for the child. Furthermore, student veterinarians may have varying levels of work experience with children (e.g. babysitting, camp counsellor positions), as well as different personal communication styles (e.g. quiet, verbose, blunt), which may impact their strengths and weaknesses in clinical communication with families. Students may benefit from self-reflection upon their own strengths and weaknesses throughout the learning process, and can consider this information in conjunction with direct feedback from supervisors. ${ }^{6,9}$

There are a number of evidence-based methods for teaching and learning communication skills in veterinary settings that can be used to enhance skill acquisition (for examples see Hecker, Adams \& Coe, 2012; McArthur, Rush, \& Nelson, 2009; Mossop et al., 2015). As communication may not be a common area of expertise in veterinary professors, ${ }^{3}$ some communication skills may be difficult to teach without consultation from those with the relevant knowledge (who may have a veterinary medicine background, or be trained in different disciplines including psychology, medicine, education). As recommended for learning any clinical skill, it is beneficial for student veterinarians to have opportunities to practice these skills with actors or real clients; a number of veterinary colleges recognize this and have already implemented opportunities in their curriculum to practice clinical skills with companion animals and their adult owners. ${ }^{2,6,21}$ Ideally, supervisors would first demonstrate appropriate communication with children for their students, and allow the students to rehearse these skills before applying them with real clients. Students would benefit from coaching and feedback 
from their supervisors regarding how to adapt their clinical communication skills to interact with both adult and child clients. Throughout this learning process, students could complete self-reflections regarding their progress in developing communication skills for child clients. ${ }^{2}$ Self-reflections include opportunities for students to compare their personal and professional communication style, note areas for improvement, and areas of strength. ${ }^{2}$ For a helpful guideline on different approaches to providing quality feedback to students, refer to Adams and Kurtz (2012) and the sample evaluation sheet in Appendix B.

Given that communication itself reflects a set of skills, training in effective communication is greatly enhanced when it emphasizes specific skills. ${ }^{18,23}$ As such, the present paper includes a number of specific communication skills that can be developed through practical experience during the TBC Tour (Appendix A), as well as various reference tools that can be studied and used before, during, and/or after administration of the tour (see Appendices B-E). It is important to distinguish between what Kurtz (2006) refers to as "content skills", defined as what one says, "process skills", which involve delivery and non-verbal communication, and "perceptual skills", which involve personal awareness and awareness of others. ${ }^{23}$ Each of these sub-groups is included in Appendix A as these different communication skills are interrelated and a weakness in one results in poorer communication overall. ${ }^{3}$ It may be beneficial for students and their supervisors to choose 3-5 specific communication skills to target during a TBC Tour, and then reflect together after the tour on the student's skill development. Additionally, this document provides useful "scripts" that student veterinarians can use verbatim, or adapt to their preference in order to describe veterinary equipment or procedures to children. The included Teaching Tip document regarding training student veterinarians in clinical communication with children and families was constructed based on literature regarding children's cognitive and language development, as well as their understanding of medical concepts. ${ }^{16,17,19,20}$ Ultimately, the primary aim of the TBC Tour method for teaching client communication is for students to develop a competence in professional clinical communication with child clientele and families.

\section{Teddy Bear Clinic Tour: An Innovative Method for Teaching Communication with Children}

Combined efforts of the Ontario Veterinary College (OVC) Smith Lane Animal Hospital and the Pediatric Pain, Health and Communication Lab (Department of Psychology) at the University of Guelph led to the development of a TBC Tour, which aimed to develop students' clinical communication skills with children through: 1) direct teaching and 2) an opportunity to practice these skills with children from the community. A TBC Tour involves student veterinarians leading groups of four to six children within the age range of 5-10 through a developmentally appropriate and interactive tour of their veterinary training facility. The children are encouraged to bring stuffed animals with them so the student veterinarians can teach children about equipment and procedures using the stuffed animals through concrete modeling and explanations.

A TBC Tour is an innovative method as it provides a unique practical opportunity for students to practice their veterinary communication skills with real children. Typically, student veterinarians practice clinical communication with adult actors, fellow students or supervisors. ${ }^{3,9}$ However, it can be difficult for an adult to imitate the developing cognitive and language abilities of a child, and therefore realistic practice of child-directed clinical communication is facilitated through interactions with children. The TBC Tour requires student veterinarians to lead and engage with small groups of children, and thus provides a valuable opportunity for student involvement, modeling, and rehearsal. ${ }^{24}$ This tour can be used in veterinary college training facilities such as hospitals and primary care centers. Students would benefit from this opportunity to practice communication with children, in a context that promotes self-reflection, peer modelling, and supervisor feedback. ${ }^{2,24}$ We believe this TBC Tour is an excellent intermediary step between students' experience learning communication skills in a classroom setting and interacting with paying clients during appointments; the 
practical resources in the Appendices of the manuscript are intended to support students and faculty in using the TBC Tour as a teaching tool.

An added benefit to running a TBC Tour is that it offers a valuable opportunity to advertise the services of a clinic and/or the quality education provided at a particular veterinary medicine college. By inviting groups of children (e.g. local children's clubs and sports teams, classrooms from local elementary schools) to their facilities, community clinics could advertise their services through a fun and interactive tour and by distributing promotional materials to parents. Furthermore, veterinary medicine colleges could use this opportunity to endorse veterinary medicine as a future career choice for children, an important value listed within the Association of American Veterinary Medical College's Strategic Plan document. ${ }^{1}$ While the TBC Tour was developed in order to teach students at the OVC strategies for communicating with children, it also provided an invaluable opportunity to advertise the new clinic (Smith Lane Animal Hospital) to the community at large. Clearly, a TBC Tour can provide a "real world" training opportunity for student veterinarians, as well as a unique grassroots marketing tool for community clinics or veterinary medicine programs.

\section{Pilot Study: Teddy Bear Clinic Tour at the Ontario Veterinary College}

As noted above, the TBC Tour was developed in collaboration with the Pediatric Pain, Health and Communication Research Lab (PPHC; Psychology Department; University of Guelph) and the Smith Lane Animal Hospital, a training clinic of the OVC. Five TBC Tours were conducted at this location with Girl Guide and Boy Scouts groups (total of 95 children) between December 2012 and March 2013. The TBC Tour included teaching children about what happens at a veterinary clinic and comparing these activities to what happens when children visit their general practitioner. ${ }^{25}$ Each tour group was split into four small groups of 4 or 5 children (both boys and girls ranging between ages 5-12) and co-led by two student veterinarians from the OVC and one research assistant from the PPHC lab. The student veterinarians who participated were third-year students at the OVC who were on rotation at the Smith Lane Animal Hospital, all of whom were required to participate in the TBC Tour. During the TBC Tour, the children visited different rooms of the Smith Lane Animal Hospital. In the Main Exam Room, they learned about a stethoscope, a needle, and an otoscope. The children also visited the Radiology Room to learn about X-Ray machines, the Rehabilitation Room to learn about physical rehabilitation exercise, and the Surgical Preparation Room (see Figure 1 for an example of a TBC Tour format). The standardized script used for the tour was designed to be easily administrable, even by volunteers who do not have experience working with young children; this script can be used as a reference for future TBC Tours. A sample of the "Main Exam Room" portion of the standardized script can be found in Appendix E, and the full script can be obtained through contacting the lead author. Student veterinarians from the OVC were trained to administer the standardized script prior to the tour by the lead researcher of the project (J. Dalley). The brief ( $<1$ hour) structured training session included reviewing the script in detail, with a focus on the use of developmentally-appropriate vocabulary to explain veterinary equipment and procedures. Following this review, the students were provided with a chance to practice the script and ask clarifying questions prior to implementing the tour. The tour was highly structured and all small groups spent the same amount of time in each area. The tour lasted approximately 45 minutes.

While no formal program evaluation was completed at the time, the supervisors of clinical training at the Smith Lane Animal Hospital anecdotally reported the TBC Tour to be an effective and novel method for teaching student veterinarians' client communication through practical application of clinical communication skills (see Appendix A). Children and families who attended the tour also found it enjoyable, likely due to its interactive nature and the focus on children's beloved stuffed animals (see Figure 2). Anecdotal evidence of challenges regarding implementing the TBC Tours at a community clinic include 1) planning logistics (e.g., recruitment of community groups, planning faculty supervision), 2) working around client appointment schedules to create space for tours, 3 ) possible unanticipated and/or negative interactions between children and 
animals, and 4) encouraging student, faculty, and staff engagement in learning communication strategies with children. Future research could investigate the efficacy of TBC Tours in teaching student veterinarian's clinical communication skills; ideal outcomes for a learning opportunity would be student and supervisor satisfaction in the process, and whether students meet their goals for clinical communication improvement. Of course, this program evaluation research would require support from clinical supervisors, faculty, and students to determine how the TBC Tour can be effectively incorporated into the curriculum to improve students' clinical communication skills.

\section{** INSERT “FIGURE 1" AND “FIGURE 2” HERE **}

\section{Teaching Communication with Children at Your Learning Facility}

The TBC Tour was formulated to be adaptable to any training clinic, and modifiable to specific rooms and equipment available at your facilities, as demonstrated in the sample TBC Tour format found in Figure 1. Present TBC Tour recommendations were generated through a combination of experience from the pilot tour, extant literature on children's language development and understanding of veterinary concepts, and veterinary education research. The recommendations are outlined in Table 2 in the order they should occur when planning a TBC Tour. The first section of Table 2 outlines the faculty's role in preparing to use the tour as an experiential teaching strategy for client communication. For example, the faculty should decide which specific communication skills will be developed through the TBC Tour and explicate these learning objectives to student veterinarians. Next, suggestions for recruiting participants for a tour are described. Following this, general recommendations for preparing student veterinarians for the tour are outlined (e.g., giving students the opportunity to learn effective client communication skills through demonstration from a supervisor before the tour, or to obtain supervisor feedback after the tour. See Appendix B). These recommendations are based on veterinary education literature; however, the organizers of each training program are encouraged to modify the process as necessary to reflect the faculty's specific learning objectives for the TBC Tour. Lastly, the resources included in the Appendices can be used as preparatory reading for student veterinarians to learn about clinical communication with children, including child-friendly veterinary terms (Appendix $C$ ), as well as how to create a child friendly-environment to support positive behavior in children (Appendix D). Student veterinarians and their supervisors can choose three to five of the communication skills listed in Appendix A as learning objectives for the TBC Tour, and then self-reflect on the development of these skills with their supervisor following the tour (e.g., see Appendix B). The sample script (Appendix E) can be used as a reference for future TBC tours, and modified to meet the specific facility and communication learning objectives of a training program.

\section{**INSERT “TABLE 2” HERE**}

\section{Summary}

Competence in professional, clinical communication with clients is associated with a variety of positive outcomes for clinicians and clients. ${ }^{3,4,6,18}$ Given that families with children are an important part of community veterinary practice, it is important that student veterinarians learn to skillfully adapt their communication style to children's language abilities and understanding of veterinary concepts. As with any learned skill, an effective way to teach this information to student veterinarians is through practical application of specific communication skills, while including student self-reflection and supervisor feedback. Thus, the objective of this paper was to provide an outline for using a TBC Tour as an experiential opportunity for teaching student veterinarian's clinical communication skills specific to children and their families. The Appendices include resources of specific clinical communication skills, a supervisor-student evaluation sheet, recommendations for supporting 
positive behavior in children, child-friendly veterinary vocabulary, and a sample script for a TBC Tour. Through following the detailed recommendations included in this Teaching Tip manuscript and Appendices, the TBC Tour can be easily utilized at your facility not only as a unique teaching method for clinical communication with children, but also as a community outreach program to advertise the services at the facility.

\section{Figure Captions}

Figure 1. A map of an example format for a Teddy Bear Clinic Tour of a veterinary facility.

Figure 2. A photo of the Pilot Teddy Bear Clinic Tour at the Smith Lane Animal Hospital (Ontario Veterinary College).

\section{Acknowledgements}

The "Teddy Bear Clinic Tour" was created as part of the honours thesis project of Jessica Dalley, in collaboration with Dr. C. Meghan McMurtry (primary supervisor), Patricia Creary, and Dr. Tiffany Durzi. This project was supported by a faculty start up fund awarded to Dr. McMurtry by the University of Guelph. We are grateful to Dr. Peter Conlon and Lisa Veit with the Ontario Veterinary College and OVC Smith Lane Animal Hospital for their collaboration. We thank the following people for their assistance in the Teddy Bear Clinic Tour: Olivia Conlon, Amanda Knoll, Rachel Tomlinson, Lara Genik, Leah Horzempa, Ayelet Freedman, Vivian King, and the participating veterinary students of the Ontario Veterinary College. 
1. AAVMC Strategic Planning Steering Committee. The Association of American Veterinary Medical Colleges strategic plan, 2010-2014. J Vet Med Educ 36(2): 154-157, 2009

2. Adams CL, Kurtz S. Coaching and feedback: Enhancing communication teaching and learning in veterinary practice settings. J Vet Med Educ 39(3): 218-228, 2012.

3. Kurtz S. Teaching and learning communication in veterinary medicine. J Vet Med Educ 33(1): 11-19, 2006.

4. Coe JB, Adams CL, Bonnett BN. A focus group study of veterinarians' and pet owners' perceptions of veterinarian-client communication in companion animal practice. J Am Vet Med Assoc 233(7): 10721080, 2008.

5. Kanji N, Coe JB, Adams CL, Shaw JR. Effect of veterinarian-client patient interactions on client adherence to dentistry and surgery recommendations in companion-animal practice. J Am Vet Med Assoc 240(4): 427-436, 2012.

6. Shaw JR, Barley GE, Hill AE, Larson S, Roter DL. Communication skills education onsite in a veterinary practice. Patient Educ Couns 80(3): 337-344, 2010.

7. Hecker KG, Adams CL, Coe JB. Assessment of first-year veterinary students' communication skills using an objective structured clinical examination: The importance of context. J Vet Med Educ 39(3): 304-310, 2012.

8. Campanella M, Lygo-Baker S. Reconsidering the lecture in modern veterinary education. J Vet Med Educ, 41(2): 138-145, 2014.

9. Martin EA. Managing client communication for effective practice: What skills should veterinary graduates have acquired for success? J Vet Med Educ 33(1): 45-49, 2006.

10. Hart LA, Yamamoto M. November 2014 Veterinary Family Practice. $<$ http://www.merckvetmanual.com/mvm/behavior/the_humananimal_bond/veterinary_family_practice.html> Accessed 10/13/2015. The Merck Veterinary Manual, Kenilworth, New Jersey, 2014.

11. Morrow V. My animals and other family. Children's perspectives on their relationships with companion animals. Anthrozoös 11(4): 218-226, 1998.

12. Tipper B. "A dog who I know quite well”: Everyday relationships between children and animals. Children's Geographies 9(2): 145-165, 2011.

13. Walsh F. Human-animal bonds I: The relational significance of companion animals. Fam Proc 48: 462480, 2009.

14. Muldon JC, Williams JM, Lawrence A. "Mum cleaned it and I just played with it": Children's perceptions of their roles and responsibilities in the care of family pets. Childhood 22(2): 201-216, 2015. 
15. Melson GF, Peet S, Sparks C. Children's attachment to their pets: Links to socio-emotional development. Children's Environments Quarterly 8(2): 55-65, 1991.

16. Santen L, \& Feldman T. Teddy bear clinics: A huge community project. MCN AM J Matern Child Nurs, 19: 102-196, 1994.

17. Zimmerman PG, Santen L. Teddy says “hi!” Teddy bear clinics revisited. J Emerg Nurs, 23(1): 41-44, 1997.

18. Shaw, JR. Four core communication skills of highly effective practitioners. Vet Clin North Am Small Anima Pract 36(2): 385-396, 2006.

19. Burbach DJ, Peterson L. Children's concepts of physical illness: a review and critique of the cognitivedevelopmental literature. Health Psychol 5(3): 307-325, 1986.

20. Rushforth H. Practitioner review: communicating with hospitalized children: review and application of research pertaining to children's understanding of health and illness. J Child Psychol Psyc 40(5): 683691, 1999.

21. Mossop L, Gray C, Blaxter A, Gardiner A, MacEachern K, Watson P, Whittlestone K, Robbé I. Communication skills training: What the vet schools are doing. Vet Rec 176(5): 114-117, 2015.

22. Hafen M Jr, Rush BR, Nelson SC. Utilizing filmed authentic student-client interactions as a communication teaching tool. J Vet Med Educ 36(4), 429-435, 2009.

23. Shaw JR, Adams CL, Bonnett BN. What can veterinarians learn from studies of physician-patient communication about veterinarian-client-patient communication? J Am Vet Med Assoc 224(5): 676684, 2004.

24. Lane IF, Cornell KK. Teaching tip: Making the most of hospital rounds. J Vet Med Educ 40(2): 145$151,2013$.

25. Dalley JS, McMurtry CM. Teddy and I get a check-up: A pilot educational intervention teaching children coping strategies for managing procedure-related pain and fear. Accepted by Pain Res Manag.

26. Sachs Hills L. Working with children: A medical practice staff training tool. J Med Pract Manage, 25(1): 29-32, 2009.

27. KidsHealth. Kids' Medical Dictionary. $<$ http://kidshealth.org/kid/word/\#cat20209>. Accessed 10/13/2015. The Nemours Foundation, 1995-2015.

28. The PBS Parents Guide to Talking with Kids about Health: Kid-Friendly Medical Dictionary. <http://www.pbs.org/parents/talkingwithkids/health/med_index.html>. Accessed 10/13/2015. PBS Parents, 2003-2015.

29. Bystrom KM, Persson C. The meaning of companion animals for children and adolescents with autism: The parents' perspective. Anthrozoös 28(2): 263-275, 2015. 
30. Kaminski M, Pellino T, Wish J. Play and pets: The physical and emotional impact of child-life and pet therapy on hospitalized children. Child Health Care 31(4): 321-335, 2002.

31. Martin F, Farnum J. Animal-assisted therapy for children with pervasive developmental disorders. West J Nurs Res 24(6): 657-670, 2002.

32. Fitzgerald H. (2013). The grieving child: A parent's guide. Simon and Schuster.

33. Sharkin BS, \& Knox D. Pet loss: Issues and implications for the psychologist. Prof Psychol-Res Pr, 34(4), 414, 2013. 
- Present yourself as a family-friendly veterinarian: It is important to introduce yourself to children, as well as parents, before an appointment or a TBC Tour. It may also be helpful for the children to clarify your role in their companion animal's care.

- Be upbeat and enthusiastic: Using a happy facial expression and variable vocal tone (vs. monotone) helps to keep the children's attention, and shows them it is fine to feel comfortable/happy in veterinary settings.

- Be aware of your body language and facial expressions: Nonverbal communication is important. ${ }^{18}$ If left unmanaged, body language can misconstrue the message you are trying to send. Try to remain “open" to your clients; for example, by keeping your arms unfolded or legs uncrossed, maintaining eye contact with the children (especially when they are speaking), and bending/crouching/squatting down to the child's level to speak with them.

- Keep it brief: Too much information can be overwhelming for younger children ${ }^{26}$ but keep in mind that older children may want you to elaborate on the information you have given.

- Use age-appropriate language: Avoid veterinary medicine jargon, and instead use descriptions/terms provided in the "Child Friendly Veterinary Terms" (Appendix C). Tell children the name of the equipment but also provide an explanation they can understand. For example, "a stethoscope lets the vet hear [companion animal's name]'s heartbeat - the vet knows what a healthy heart sounds like!"

- Use literal and concrete explanations for young children: Be careful about how you phrase things, as certain terms or phrases may confuse or frighten some children. Abstract concepts (e.g., health and illness) can be difficult for younger children to understand. ${ }^{19,20}$ For example, children might become frightened if you tell them "In surgery, we open [companion animal's name] up." Rather, say something like "Sometimes [companion animal's name] may need surgery, which means that the vet will put him/her to sleep for a little while with some special medicine. This makes it so that [companion animal's name] will not feel any pain or hurt while the surgery is happening, because the vet needs to work inside [companion animal's name]'s body." Older children may follow up with more questions, and also may prefer more detailed, abstract explanations.

- Pay attention to the way that children are talking: Try to mirror children's communication by incorporating their own wording in your explanations to increase their attentiveness and understanding. It is equally important to pay attention to how children are communicating non-verbally (e.g. facial expressions indicating they are uncomfortable or nervous, such as wide eyes or looking down; body language indicating they are distracted or not engaged). This can help you to determine children's emotions and understanding of the task at hand.

- Use play to engage children in conversation and learning: The TBC Tour uses play as a valuable tool to engage children in fun and educational conversations, help them better understand veterinary equipment, and help them feel more comfortable in a veterinary setting. It is recommended veterinarians use age-appropriate play, where possible, to engage children in communication.

- Promote veterinary visits as positive experiences: One of the main objectives of improving communication with families in community veterinary clinics is to ensure children have positive attitudes about veterinary settings and procedures. By talking about procedures and equipment in a positive way, it shows that you are comfortable and the child can be too. Compare what you are doing/talking about to things children do to stay healthy, such as brushing their teeth or eating well. You can put it in visual/concrete terms for the children by saying something like "[Companion animal's name] is like a NASCAR driver and this is just a pit stop to make sure he/she still has air in the wheels, gas in the tank, etc." 
- Encourage questions: Conversations during appointments or a TBC Tour should be interactive, so you may need to slow down your pace to pause for children to think about what they've learned and then ask questions. Asking questions allows children to learn more and feel in control, and it may help make them less fearful. ${ }^{26}$

- Give children a task: Through actively involving children in a task (e.g. asking children to hand an object to you, or to tell you the name of a piece of equipment) you will gain both their interest and compliance. $^{26}$

- Praise: Praise is positive reinforcement and used appropriately leads to better behavior. ${ }^{26}$ To be effective, praise must be specific, genuine, and immediately follow the desired behavior (e.g., Thank you for listening so well- I can tell you really want to learn more about your dog's health!').

- Be empathic: Empathic and effective communication demonstrates that the veterinary team appreciates how important the companion animal is to the child and their family (see Appendix E for empathic and child-friendly descriptions of serious veterinary procedures). 
Student Name:

Date of Classroom Practice:

Students are encouraged to pick 3-5 specific communication skills to practice during the tour.

STUDENT GOAL-SETTING (completed before the tour)

Client Communication

Strengths

Client Communication

Areas for Improvement

The communication skills I will practice through the TBC Tour are:

1.

2.

3.

Students and supervisors are encouraged to reflect on student development of these skills after the tour.

STUDENT SELF-REFLECTION \& SUPERVISOR EVALUATION (completed after the tour):

\begin{tabular}{|l|l|}
\hline WHAT WENT WELL & \\
\hline & AREAS FOR IMPROVEMENT \\
\hline & \\
\hline Next Steps (these should be specific and measureable): \\
\hline$\bullet$
\end{tabular}


General Introduction of the Instruments: Sometimes your doctor can't see what's happening in your body just by looking at you. This is the same for vets and animals. We can't tell what's happening with your pet without special tools. These tools are used to get a closer look inside an animal's body to make sure everything in there is healthy.

Note: with younger children, it is important to frequently repeat that each instrument helps the vet to see parts of the body better to help keep the animal healthy.

\section{Child-Friendly Phrasing for Veterinary Equipment \& Procedures}

Thermometer: We can use this thermometer to find out if [companion animal's or teddy's name] body is too hot, too cold, or just right. If [companion animal's or teddy's name] is very warm, the vet may give him/her some medicine to make him/her feel better.

Otoscope: This is like a little telescope with a small light on the end of it that is used to see the inside of [companion animal's or teddy's name] ear better.

Ophthalmoscope: This is a flashlight that the veterinarian uses to see into [companion animal's or teddy's name] eyes. This lets the vet get a better look at [companion animal's or teddy's name] eyes, and the light helps to spot any problems if there are any.

Stethoscope: This is used to hear the different sounds inside of [companion animal's or teddy's name]'s body. Normally, the vet can't hear sounds like a heartbeat or air moving in and out of lungs, but with the stethoscope, the sounds get much louder. ${ }^{27}$ It's like turning up the volume on the TV. The vet may listen to [companion animal's or teddy's name]'s heart in a couple of different places (e.g., chest, back).

Syringes: This is a needle. Sometimes it's used to take [companion animal's or teddy's name]'s blood so the vet can take a closer look. The blood goes into the little tube here. It's really cool, because the veterinarian gets to look at the blood close up to make sure [companion animal's or teddy's name] is healthy. Needles can also be used to give medicine to the inside of [companion animal's or teddy's name]'s body. This medicine keeps your [companion animal] healthy!

X-Ray: Instead of taking a picture of the outside of [companion animal's or teddy's name]'s body, like a normal camera would, an X-Ray takes a picture of the bones inside of [companion animal's or teddy's name]'s body to make sure they aren't broken and are in the right place. [Companion animal's or teddy's name] won't feel anything while the vet uses the X-ray machine to take its pictures. ${ }^{27,28}$

\section{Discussing Serious and/or Potentially Distressing Information:}

As student veterinarians know, communicating with clients can be especially difficult when the veterinarian must deliver emotionally upsetting news, and/or if the companion animal is injured or ill. Student veterinarians may be faced with the challenge of discussing difficult topics with children who are old enough to want information about their companion animal's health. First and foremost, parents must give permission for the child to be involved in serious veterinary communications regarding their companion animal. In cases where the parent and children are present during veterinary appointments, it is important to be sensitive to 
children's feelings, and the significant role that companion animals have in children's lives. ${ }^{9}$ The ability to empathize is integral to maintaining a quality professional relationship with clients of any age. ${ }^{5}$ While student veterinarians need not fully explore children's negative feelings, empathic and sensitive communicators use developmentally appropriate language, and acknowledge appreciation of why the child is feeling worried or sad. Children view their companion animals as part of their family. ${ }^{9}$ Research on the human-animal bond also indicates that children obtain various socio-emotional and psychological benefits from animal-assisted activities ${ }^{29,30,31}$ and companion animal ownership. ${ }^{11}$ Given that companion animals can be a source of social and emotional support for young children, it is reasonable that they want knowledge regarding their companion animals' well-being and may be emotional if the companion animal is ill or injured. Additionally, the death of a child's companion animal may be the child's first experience with death of a loved one (e.g. see Fitzgerald, 2013 and Sharkin \& Knox, 2003 for more information regarding children's bereavement of a companion animal).

Surgery: Sometimes animals need to have an operation or surgery. Veterinarians can perform an operation on a pet for many reasons. Usually it is because something inside the body needs to get fixed and it can't be done just with medicine. An example is when an animal eats a toy. The veterinarian may need to operate on an animal to remove the toy from its stomach. If the operation wasn't done, the pet would get very sick or feel a lot of pain or hurt.

Euthanasia: In animal medicine, we are able to end the suffering of a pet. If a pet is in a lot of pain/hurt, or its body isn't working right anymore and we can't make things better, we may consider euthanasia. Euthanasia is when we help the pet die peacefully and without pain. This is a very serious decision that veterinarians and families make together. Some families might feel very sad when this happens, and that's okay - it's important to talk to your moms and dads about how you feel when a pet dies.

If a child seems confused, or asks for more information on how an animal dies via euthanasia: When the veterinarian and family decide together that euthanasia is the best way to help a pet, the veterinarian will give the pet special drugs so that the pet will die. It is very quick and painless. This kind of drug is for very sick pets only.

Getting your pet spayed/neutered: Many pet owners will have their pet spayed or neutered. This means a pet will have an operation so that it won't be able to have kittens or puppies. Sometimes it can also help make sure a pet won't get sick later on. If it is a female or girl pet, then we call the surgery a spay. If it is a male or boy pet, we call the surgery a neuter. Although it is fun to have puppies and kittens, it is important to control how many pets are born. For example, there aren't enough good homes for puppies if a dog has 10-16 puppies at a time.

Anesthesia induction: Anesthesia is a special medicine that helps an animal dog sleep during surgery and makes it so that the animal won't feel any pain while the vet is working on his/her body. There are different ways that the veterinarian can give an animal the anesthetic, a special medicine, before the surgery starts. The anesthesia can be breathed in through a special mask that the animal wears, or it can be given by the veterinarian using a needle. 
Remember, children will be accompanied by their parents, who will ideally remain in charge of their children's behavior. However, if you are finding a child's behavior distracting or disruptive, the recommendations below provide guidelines for supporting positive behavior in children ages 5-10. Proactive use of techniques one through five will reduce behavioral issues, and techniques six and seven are useful for when behavioral problems develop.

1. If conducting a tour, use small groups: Smaller groups of children will generally result in less behavioral issues and will make children more comfortable.

2. Make the rules clear: Tell the children up front what you expect and be clear. When possible if correcting behavior, indicate what behaviors you want to see, rather than what ones to avoid (e.g., "Walk please" vs. "don't run"). Although minor behavioral issues can be ignored, be consistent in correcting dangerous or highly disruptive behavior. Praise desirable behavior.

3. Be engaging: Try to include the children as much as possible by using humor, asking them simple questions, and checking in to make sure they understand. Keeping the visit as interactive as possible and minimizing the time spent "lecturing" will cause children to be more attentive (e.g., "Raise your hand if you've ever had your temperature taken"). Allowing the children to play with or look at safe equipment gives them a chance to become familiar with veterinary equipment and may make them more comfortable with seeing it (e.g., needles become less scary to look at).

4. Use structure and transitional warnings: Keeping a predictable and structured schedule helps children transition to different activities. Children may have a hard time with transitions, therefore it is important to give plenty of time warnings. For example: "We just finished talking about bandages, and now we will be talking about needles" or "We have one minute left in this exam room, and then we are going to move to the next room where we will look at X-Rays!"

5. Provide structured choices: Children, particularly younger children, respond best when they are given structured or forced-choice questions (two options at a time) compared to open-ended questions. For example, say "Would you like to look at bandages or tongue depressors first?" rather than "What should we look at first?" When asking a child to participate, be aware of your wording to ensure that you are still in control of what happens next (e.g., "Would you like to help me with now or should I do it on my own?" instead of "Is it ok if we do this now?").

6. Be flexible: There is usually a reason why children are acting the way they are (e.g., chatty, fidgety) they are not necessarily trying to be disrespectful. They might be bored or nervous. Be sure to pay attention to children's' nonverbal cues and respond accordingly.

7. If children are being inattentive: If children are not listening, get down to their level (if not already) and establish eye contact and say something like, "It's time for you and your dog to put your listening ears on." Alternatively, you could emphasize the importance of the information to the child's parent. For example, "I think your parents would like to hear this part, so let's make sure that he/she can hear what the vet is saying!" 
*As used in pilot TBC Tour at Ontario Veterinary College, University of Guelph. For full script, please contact the lead author or see Dalley \& McMurtry (2015).

The purpose of the main examination room is to teach the children about the different instruments used by veterinarians. Have the children stand on the other side of the examination table from you. Begin by introducing yourself, and have all the children take turns telling you their names and the names of their stuffed animals. Remember to speak clearly and enthusiastically. When speaking directly to a child, remember to use their name and the name of their stuffed animal.

1) Discuss why it is important for people to go to doctors and their pets to go to the veterinarian. "We might go to the doctor if we are feeling sick, but we also need to go to the doctor - even if we feel fine - to make sure that everything is working properly and that we are strong and healthy. The same is true for your pets. Your stuffed animal is here today to have a check-up, and if anything is wrong with him/her we can help your stuffed animal out. After all, that's what doctors and veterinarians are for - to make you sure you and your stuffed animal are healthy and happy!”

2) Introduce the veterinary instruments. Before we fix each of your stuffed animals, we will explain some of the tools that veterinarians can use to look at an animal's body. The veterinarians can't always see what's happening in an animal's body just by looking at them, so they may need to use special tools. These tools are used to get a closer look inside an animal's body to make sure everything in there is running smoothly. You and I can work together to make sure your stuffed animal is healthy.

\section{3) Discuss the name, function and 'feel' of needles.}

Name: Hold up a syringe. "Does anyone recognize this? This is a needle, and it can be used for a few things." Function: "It can be used to take a little bit of your stuffed animal's blood to send for tests. The needle only takes a tiny bit of blood, and it goes into the little tube here. That's really important, because the veterinarian gets to look at the blood close up to make sure your stuffed animal is healthy. Needles can also be used to give medicine to the inside of your stuffed animal's body. Animals might need this medicine so that they don't get sick."

Feel: "Raise your hand if you have ever gotten a needle before. Needles have a sharp point at the end and this can hurt you. This means needles are only safe for a veterinarian, doctor, or trained person to use."

Demonstration: After demonstrating how the needle is used on the Ontario Veterinary College's stuffed animal, give each child's stuffed animal a 'fake needle', using a syringe without a needle in it. Remember to immediately dispose of the needle and place a Band-Aid on the stuffed animal.

\section{4) Discuss the name, function and 'feel' of a stethoscope.}

Name: Hold up a stethoscope. "Does anyone know what this is? This is called a stethoscope - can everyone say stethoscope? ... Terrific!"

Function: "Veterinarians use this to hear the different sounds inside of your stuffed animal's body. Usually, the veterinarian can't hear sounds like an animal's heart beat or air moving in and out of their lungs, but with the stethoscope, the sounds get much louder. It's like turning up the volume on the TV."

Feel: "Veterinarians might listen to your stuffed animal's heart or breathing in a couple of different places, so they might put the stethoscope on their chest or back so that things sound louder! Put the stethoscope on different parts of your arm (or the other tour leader's) to show children it feels fine.

Demonstration: "Let's listen to your stuffed animal's heartbeat together." If the children want to hear a 
803

heartbeat, put the stethoscope up to your chest (or the other tour leader's), not the children's, so they can listen.

804

805

806

807

808

809

810

811

812

813

814

815

816

817

818

819

820

821

822

823

824

825

826

827

829

830

831

832

833

834

835

836

837 